\title{
Clinical neurorestorative progress in amyotrophic lateral sclerosis
}

This article was published in the following Dove Press journal:

Journal of Neurorestoratology

6 August 2015

Number of times this article has been viewed

\section{Lin Chen ${ }^{1,2,5}$ \\ Hongyun Huang ${ }^{3}$ \\ Haitao $\mathrm{Xi}^{4,5}$ \\ Gengsheng $\mathrm{MaO}^{3}$}

'Medical Center, Tsinghua University, ${ }^{2}$ Tsinghua University Yuquan Hospital, ${ }^{3}$ General Hospital of Chinese People's Armed Police Forces, ${ }^{4}$ Beijing Rehabilitation Hospital of Capital Medical University, ${ }^{5}$ Beijing Hongtianji Neuroscience Academy, Beijing,

People's Republic of China
Correspondence: Lin Chen Tsinghua University Yuquan Hospital, 5 Shijingshan Road, Beijing, Republic of China Email chenlin_china@।63.com

Hongyun Huang

General Hospital of Chinese People's Armed Police Forces, 69 Yongding Road, Haidian District, Beijing, People's Republic of China Email hongyunh@gmail.com
Abstract: Amyotrophic lateral sclerosis is a progressive and fatal neurodegenerative disease characterized by progressive paralysis and motor neuron death. In addition to symptomatic managements such as ventilation and nutritional support, neurorestorative therapies have demonstrated anti-neurodegenerative potential and may improve quality of life for patients. Currently, clinical neurorestorative strategies include pharmacological management (granulocyte colony stimulating factor), neuromodulatory intervention (repetitive transcranial magnetic and cortical stimulation), cell transplantation (bone marrow stromal cells, olfactory ensheathing cells, granulocyte colony stimulating factor-mobilized peripheral blood stromal cells, hematopoietic stem and progenitor cells, neural stem/progenitor cells, CD133+ cells and CD34+ cells), bioengineering and tissue engineering therapy, and combined neurorehabilitative treatment. In this review, we describe the latest progress in clinical neurorestorative management of amyotrophic lateral sclerosis and discuss the underlying evidence base.

Keywords: amyotrophic lateral sclerosis, neurorestorative treatment, cell transplantation, clinical trial

\section{Introduction}

Amyotrophic lateral sclerosis (ALS) is characterized by degenerative changes in the upper and lower motor neurons, resulting in progressive muscle atrophy and weakness, increased fatigue, and problems with swallowing, that typically lead to respiratory failure and death within 3-5 years after diagnosis. ${ }^{1}$ The incidence of sporadic ALS was reported to be $1.5-2.7$ per 100,000 population per year (average 1.89 per 100,000 per year) in Europe and the USA during the 1990's. ${ }^{2}$ The mean age of onset for sporadic ALS varies between 55 and 65 years, with a median of 64 years. $^{3}$

The exact cause and molecular pathway for ALS remain unknown. There is likely to be a complex interplay between multiple pathogenic cellular mechanisms that may not be mutually exclusive, including genetic factors, ${ }^{4}$ excitotoxicity, ${ }^{5}$ oxidative stress, ${ }^{6,7}$ mitochondrial dysfunction, ${ }^{8}$ axonal transport dysfunction, ${ }^{9}$ neurofilament aggregation, ${ }^{10-12}$ protein aggregation, inflammatory dysfunction, and a contribution of glial cells and deficits in neurotrophic factors.

Three effective treatments have been recommended for prolonging survival in ALS patients, ie, multidisciplinary team care, mechanical ventilation, and gastrostomy tubes. ${ }^{13,14}$ Riluzole is the only approved drug that has shown a modest effect on prolonging survival in ALS patients (about 3 months). ${ }^{15}$ There are plenty of undergoing clinical trials, and in this mini-review the authors highlight and summarize the progress 
in clinical neurorestorative management of ALS through cell-based neurorestorative strategies.

\section{Clinical neurorestorative progress Medicines}

Lithium and valproate cotreatment increases survival of ALS patients by neuroprotection, which can be observed from levels of biochemical markers, such as $\mathrm{Cu} / \mathrm{Zn}$ superoxide dismutase and glutathione peroxidase activity, and reduced glutathione, ${ }^{16}$ although a randomized sequential Phase IIb trial showed that lithium alone lacked an effect on survival in ALS. ${ }^{17}$ As a potential therapy, vitamin D has been demonstrated to influence multiple aspects of ALS pathology and may provide a cumulative effect. ${ }^{18}$ Preliminary human exposure data showed that injection of granulocyte-colony stimulating factor (G-CSF) was safe and feasible during a 3-year observation period. ${ }^{19}$

\section{Neuromodulation}

\section{Repetitive transcranial magnetic stimulation}

Repetitive transcranial magnetic stimulation (rTMS) of the brain can modulate cortical neurotransmission. A novel paradigm of repetitive stimulation termed continuous theta-burst stimulation can produce pronounced and prolonged suppression of motor cortex excitability. In 2004, Di Lazzaro et al reported the clinical results of rTMS of the motor cortex at low $(1 \mathrm{~Hz})$ or high $(20 \mathrm{~Hz})$ frequencies in 20 ALS patients. The treatment was well tolerated. The rate of progression during treatment was slightly slower than previous treatment in patients exposed to low-frequency rTMS. ${ }^{20}$ However, in a further double-blind, placebo-controlled trial by the same research group, there was no significant difference in deterioration on the revised Amyotrophic Lateral Sclerosis Functional Rating Scale (ALS-FRS) between patients treated with real or sham stimulation. ${ }^{21}$ Another report indicated that $5 \mathrm{~Hz}$ rTMS may improve motor function and quality of life in ALS. ${ }^{22}$

\section{Surgical stimulation of the cortex}

Four consecutive ALS patients were treated surgically with bilateral chronic cortical stimulation. Two years later, the first two patients demonstrated mild progression of their illness, and single-photon emission computerized tomography findings showed complete disappearance of cerebral ALS lesions, with apparent recovery of brain anatomic integrity. The third patient committed suicide, and the fourth showed transient improvement during the first 3 months after surgery. ${ }^{23}$

\section{Neurorehabilitation}

Neurorehabilitation as a complementary or alternative neurorestorative strategy may play a role in improving patient survival rates and maintaining functional independence as well as quality of life. ${ }^{24}$ However, more research is needed to decisively determine the effect of exercise on the ALS patients. ${ }^{25,26}$ Recently, repetitive rhythmic exercise mediated by supported treadmill ambulation training has been shown to be feasible, well tolerated, and safe, and can improve work capacity and gait function in patients with ALS who are dependent on assistive devices for ambulation. ${ }^{27}$ Moderate evidence indicates that an occupational therapy-related home exercise program of daily stretching and resistance exercise results in improved function. ${ }^{28}$

\section{Cell therapy}

Cell-based treatment represents a new approach offering a neuroprotective environment for degenerating motor neurons, cellular replacement of lost motor neurons, and/or trophic support. ${ }^{29}$ An increasing amount of data show a crucial therapeutic value in ALS. Combination therapy consisting of various cell types may provide a comprehensive treatment for ALS. ${ }^{30}$

\section{Bone marrow stromal cells}

Mesenchymal stromal cell (MSC) transplantation modulates the neuroinflammatory milieu and motor neuronal and glial response to apoptosis and inflammation in ALS. ${ }^{31,32}$ In 2003, Mazzini et al reported the feasibility and safety of a method of intraspinal cord implantation of autologous bone marrow stromal cells (BMSCs) in ALS patients with no major adverse events. ${ }^{33}$ In 2006, the same group showed a significant slowing down of the linear decline of forced vital capacity in four of seven patients 36 months after BMSC transplantation. ${ }^{34}$ Next, they reported no significant late side effects from intraspinal injections of autologous BMSCs at the thoracic level after monitoring for 4 years. ${ }^{35}$ Four patients showed significant slowing down of the linear decline in forced vital capacity and ALS-FRS score. Magnetic resonance images in ten cases revealed no structural changes (including tumor formation) in either the brain or spinal cord. ${ }^{36}$

Intrathecal and intravenous transplantation of BMSCs are clinically feasible and relatively safe procedures, and can have immediate immunomodulatory effects. ${ }^{37}$ BMSCs at earlier passages are more suitable for cell therapy in ALS patients because of their stability and more potent antiinflammatory and neuroprotective properties. ${ }^{38}$ But ALS 
BMSCs diminish their trophic mediator capacity and might reduce beneficial effects in cell therapy. ${ }^{39}$

Martínez et al recently described a young woman with rapidly progressive ALS in whom cell injection was performed by lumbar puncture without changes. After bilateral autologous cell transplantation into the frontal motor cortices, stabilization and improved quality of life were observed. ${ }^{40}$

\section{Olfactory ensheathing cells}

Considering the potential risks of cell transplantation following spinal cord surgery under general anesthesia in ALS patients, Huang et al and Chen et al proposed the key point (bilateral corona radiata in the frontal lobes) for restoration of the neural network in the brain based on a set of successful cases in clinical practice. ${ }^{41,42}$ The evidence showed that neural network restoration via cell transplantation under local anesthesia is safer and better tolerated, especially in ALS patients with impaired breathing. In total, 327 patients (241 males and 86 females) with probable or definite ALS received olfactory ensheathing cell (OEC) transplantation. The rate of total improvement in neurological function was $77.1 \%$ (252/327) with spontaneous potential diminution and/or disappearance on electromyographic examination. ${ }^{43}$ In a series of OEC transplantation studies, seven ALS patients were studied by proton magnetic resonance spectroscopy and their improvement in ALS-FRS was confirmed by electromyography, ie, the $\mathrm{N}$-acetylaspartate/creatine ratio increased in the certain anatomic position of brain (cerebral peduncle, genu and posterior limb of the internal capsule, corona radiata and precentral gyrus). ${ }^{44}$ In a controlled pilot study involving 35 patients with probable or definite ALS by assessment of revised ALS-FRS, there was no significant difference in rate of progression during the first 2 months $(P>0.05)$; however, the functional deterioration was significantly slower in the treated group than in the control group during the last 2 months $(P<0.05) .{ }^{45}$ More excitingly, patients with multiple times of cell transplantation and long-term observation definitely showed that patients with multiple times of cell transplantation could have neurological functional and breathing ability recovery after each cell therapy, majority of which were confirmed by electromyography and pulmonary function tests. ${ }^{46}$

\section{Peripheral blood stromal cells mobilized by G-CSF} Cashman et al conducted a small pilot trial of the collection and reinfusion of G-CSF-mobilized peripheral blood stromal cells in ALS patients and found no adverse effects. ${ }^{47}$

\section{Allogeneic hematopoietic stem cells}

Allogeneic hematopoietic stem cell transplantation was performed in patients with sporadic ALS, and improved clinical outcomes were reported..$^{48}$

\section{Bone marrow-derived hematopoietic progenitor cells}

Thirteen patients with sporadic ALS were treated with bone marrow-derived hematopoietic progenitor cells. A total laminectomy was performed at the $\mathrm{C} 1-\mathrm{C} 2$ level under general anesthesia, and cells were injected into the anterior part of the spinal cord. Nine patients improved, as confirmed by electroneuromyography during a year of follow-up after cell implantation. ${ }^{49}$

\section{$\mathrm{CDI} 33^{+}$and $\mathrm{CD} 34^{+}$cells}

Five men and five women with confirmed ALS were treated by autologous peripheral blood $\mathrm{CD} 133^{+}$cells and showed a statistically significant increase in survival when compared with untreated control patients for 1 year. ${ }^{50}$ Cordes at al reported a 63-year-old male ALS patient who underwent intramedullary thoracic spinal cord implantation of human $\mathrm{CD} 4^{+}$umbilical cord-derived hematopoietic progenitor cells with a 3-year follow-up and showed a positive outcome. ${ }^{29}$

\section{Neural stem/progenitor cells}

Riley et al reported that neural stem/progenitor cell transplantation into the cervical or thoracolumbar spinal cord was well tolerated. ${ }^{51,52}$ Feldman et al completed an openlabel, first-in-human, Phase I feasibility and safety study of human spinal cord-derived neural stem cell transplantation in 12 ALS patients. The results showed that the approach of cervical and dual-targeted intraspinal transplantation was feasible and well tolerated. ${ }^{53}$

\section{Bioengineering and tissue engineering}

Nerve growth factor holds promise for providing therapeutic benefits in ALS. The initial trials focusing on systemic delivery of ciliary neurotrophic factor (CNTF) for ALS have been frustrating because of major peripheral side effects, the molecule's short half-life, and its inability to cross the blood-brain barrier, thus preventing determination of the potential efficacy of the molecule. In order to deliver CNTF directly into the nervous system, Aebischer et al conducted a Phase I study in which six ALS patients were implanted with polymer capsules containing approximately $10^{6}$ genetically engineered baby hamster kidney cells, which provided slow continuous release of human $\mathrm{CNTF}$ at a rate of 0.25 to 1.0 
(mean 0.5) g/24 hours in vitro. ${ }^{54,55}$ A further Phase I/II clinical trial was performed in 12 patients to evaluate the safety and tolerability of intrathecal implants of genetically engineered encapsulated baby hamster kidney cells releasing human CNTF. The results indicated that cells could survive for up to 20 weeks in the absence of immunosuppression, without any adverse effects in implanted patients. ${ }^{56}$

\section{Discussion}

\section{Possible mechanisms of neurorestoration by cell therapy Olfactory ensheathing cells}

These are a specific type of glial cell residing in the olfactory system and are reported to help promote regeneration and remyelination in the brain and spinal cord. ${ }^{57}$ Neonatal OECs transplanted into the dorsal funiculus of the spinal cord in mutant SOD1 (G93A) transgenic rats can increase survival of spinal motor neurons and remyelinate impaired axons of the pyramidal tract. ${ }^{58}$ When OECs were injected stereotactically into the corona radiata of SOD1 mutant adult rats, more motor neurons at both the motor cortices and ventral horns of the spinal cord survived in grafted ALS rats than in control rats. Prolonged survival and results for behavioral tests, including a screen test, hind limb extension, the RotaRod test, and gait control demonstrated that the treated animals fared better than the control group. ${ }^{59}$ Further research is needed to determine the optimal dose and delivery route, and standardize cell cultures.

\section{Mesenchymal stromal cells}

MSCs might be suitable for ALS because of their immunomodulatory and protective properties and their ability to differentiate into several specific cell types, including neural cells. Because of their unique properties, MSCs are playing a key role in treatment strategies for ALS. Intravenous injection of human MSCs into presymptomatic, irradiated G93A mice could delay onset of the disease and slow its progression in recipient mice, and also increase their lifespan. ${ }^{60}$ Intraparenchymal delivery of MSCs is safe, and can delay loss of motor neurons and prolong motor performance. ${ }^{61}$ More detailed mechanism research including trophic factor delivery, anti-inflammatory and angiogenesis is on the way, and combination of cells is an important direction in the treatment of ALS for a better outcome.

\section{Possible mechanisms of neuromodulation in ALS}

It has been proposed that glutamate-related excitotoxicity may promote death of motor neurons in ALS. Glutamatergic circuits in the human motor cortex can be activated noninvasively using transcranial magnetic stimulation of the brain, and rTMS can produce changes in neurotransmission that outlast the period of stimulation. Studies have shown that rTMS of the motor cortex at frequencies that decrease cortical excitability cause a slight slowing in the progression of ALS, suggesting that these effects might be related to a diminution of glutamate-driven excitotoxicity. rTMS might also interfere with death of motor neurons through different mechanisms, ie, rTMS could modulate the production of brain-derived neurotrophic factor, which in turn might represent a promoter of motor neuron sparing in ALS. ${ }^{62}$

In summary, ALS continues to be a fatal neurodegenerative disorder, and the challenge is still to develop effective targeted therapeutic interventions, among which cell therapy represents an important initial step, being able to stabilize or even improve neurological functioning and quality of life in ALS patients for a period of time. With improved recognition of the mechanisms of neurorestoration and the complex interplay of several factors that may contribute to the pathogenesis of ALS, in addition to improved patient selection criteria, outcome measures, biomarkers for therapy development, ${ }^{63}$ clinical translation of cell-based comprehensive neurorestorative strategies combined with symptomatic treatment, which should cover the whole period from the moment the disease is diagnosed to its terminal phase, patients' independence will be prolonged and their quality of life improved.

\section{Acknowledgment}

We thank Lu Zheng and Jiangfeng Guo for collecting the relevant data for preparing this manuscript.

\section{Disclosure}

The authors report no conflicts of interest in this work.

\section{References}

1. Sejvar JJ, Holman RC, Bresee JS, Kochanek KD, Schonberger LB. Amyotrophic lateral sclerosis mortality in the United States, 1979-2001. Neuroepidemiology. 2005;25:144-152.

2. Worms PM. The epidemiology of motor neuron diseases: a review of recent studies. J Neurol Sci. 2001;191:3-9.

3. Haverkamp LJ, Appel V, Appel SH. Natural history of amyotrophic lateral sclerosis in a database population. Validation of a scoring system and a model for survival prediction. Brain. 1995;118:707-719.

4. Rosen DR, Siddique T, Patterson D, et al. Mutations in Cu/Zn superoxide dismutase gene are associated with familial amyotrophic lateral sclerosis. Nature. 1993;362:59-62.

5. Rothstein JD, Van Kammen M, Levey AI, Martin LJ, Kuncl RW. Selective loss of glial glutamate transporter GLT-1 in amyotrophic lateral sclerosis. Ann Neurol. 1995;38:73-84.

6. Ferrante RJ, Browne SE, Shinobu LA, et al. Evidence of increased oxidative damage in both sporadic and familial amyotrophic lateral sclerosis. J Neurochem. 1997;69:2064-2074. 
7. Smith RG, Henry YK, Mattson MP, Appel SH. Presence of 4-hydroxynonenal in cerebrospinal fluid of patients with sporadic amyotrophic lateral sclerosis. Ann Neurol. 1998;44:696-699.

8. Ro LS, Lai SL, Chen CM, Chen ST. Deleted 4977-bp mitochondrial DNA mutation is associated with sporadic amyotrophic lateral sclerosis: a hospital-based case-control study. Muscle Nerve. 2003;28:737-743.

9. Reid E, Kloos M, Ashley-Koch A, et al. A kinesin heavy chain (KIF5A) mutation in hereditary spastic paraplegia (SPG10). Am J Hum Genet. 2002;71:1189-1194.

10. Hirano A, Donnenfeld H, Sasaki S, Nakano I. Fine structural observations of neurofilamentous changes in amyotrophic lateral sclerosis. J Neuropathol Exp Neurol. 1984;43:461-470.

11. Hirano A, Nakano I, Kurland LT, Mulder DW, Holley PW, Saccomanno G. Fine structural study of neurofibrillary changes in a family with amyotrophic lateral sclerosis. J Neuropathol Exp Neurol. 1984;43:471-480.

12. Carpenter S. Proximal axonal enlargement in motor neuron disease. Neurology. 1968;18:841-851.

13. Miller RG, Jackson CE, Kasarskis EJ, et al. Practice parameter update: the care of the patient with amyotrophic lateral sclerosis: drug, nutritional, and respiratory therapies (an evidence-based review): report of the Quality Standards Subcommittee of the American Academy of Neurology. Neurology. 2009;73:1218-1226.

14. Miller RG, Jackson CE, Kasarskis EJ, et al. Practice parameter update: the care of the patient with amyotrophic lateral sclerosis: multidisciplinary care, symptom management, and cognitive/behavioral impairment (an evidence-based review): report of the Quality Standards Subcommittee of the American Academy of Neurology. Neurology. 2009;73:1227-1233.

15. Zoccolella S, Santamato A, Lamberti P. Current and emerging treatments for amyotrophic lateral sclerosis. Neuropsychiatr Dis Treat. 2009;5:577-595.

16. Boll MC, Bayliss L, Vargas-Cañas S, et al. Clinical and biological changes under treatment with lithium carbonate and valproic acid in sporadic amyotrophic lateral sclerosis. J Neurol Sci. 2014;340:103-108.

17. Verstraete E, Veldink JH, Huisman MH, et al. Lithium lacks effect on survival in amyotrophic lateral sclerosis: a phase IIb randomised sequential trial. J Neurol Neurosurg Psychiatry. 2012;83:557-564.

18. Gianforcaro A, Hamadeh MJ. Vitamin D as a potential therapy in amyotrophic lateral sclerosis. CNS Neurosci Ther. 2014;20:101-111.

19. Grassinger J, Khomenko A, Hart C, et al. Safety and feasibility of long term administration of recombinant human granulocyte-colony stimulating factor in patients with amyotrophic lateral sclerosis. Cytokine 2014;67:21-28.

20. Di Lazzaro V, Dileone M, Pilato F, et al. Repetitive transcranial magnetic stimulation for ALS. A preliminary controlled study. Neurosci Lett. 2006;408:135-140.

21. Di Lazzaro V, Pilato F, Profice P, et al. Motor cortex stimulation for ALS: a double blind placebo-controlled study. Neurosci Lett 2009;464:18-21.

22. Zanette G, Forgione A, Manganotti P, Fiaschi A, Tamburin S. The effect of repetitive transcranial magnetic stimulation on motor performance, fatigue and quality of life in amyotrophic lateral sclerosis. J Neurol Sci. 2008;270:18-22.

23. Sidoti C, Agrillo U. Chronic cortical stimulation for amyotrophic lateral sclerosis: a report of four consecutive operated cases after a 2-year follow-up: technical case report. Neurosurgery. 2006;58:E384.

24. Orient-Lopez F, Terre-Boliart R, Guevara-Espinosa D, BernabeuGuitart M. Neurorehabilitation treatment of amyotrophic lateral sclerosis. Rev Neurol. 2006;43:549-555.

25. Lewis M, Rushanan S. The role of physical therapy and occupational therapy in the treatment of amyotrophic lateral sclerosis. NeuroRehabilitation. 2007;22:451-461.

26. Kühnlein P, Gdynia HJ, Sperfeld AD, et al. Diagnosis and treatment of bulbar symptoms in amyotrophic lateral sclerosis. Nat Clin Pract Neurol. 2008;4:366-374.
27. Sanjak M, Bravver E, Bockenek WL, Norton HJ, Brooks BR. Supported treadmill ambulation for amyotrophic lateral sclerosis: a pilot study. Arch Phys Med Rehabil. 2010;91:1920-1929.

28. Arbesman M, Sheard K. Systematic review of the effectiveness of occupational therapy-related interventions for people with amyotrophic lateral sclerosis. Am J Occup Ther. 2014;68:20-26.

29. Cordes AL, Jahn K, Hass R, et al. Intramedullary spinal cord implantation of human CD34(+) umbilical cord-derived cells in ALS. Amyotroph Lateral Scler. 2011;12:325-330.

30. Lunn JS, Hefferan MP, Marsala M, Feldman EL. Stem cells: comprehensive treatments for amyotrophic lateral sclerosis in conjunction with growth factor delivery. Growth Factors. 2009;27: 133-140.

31. Sun H, Bénardais K, Stanslowsky N, et al. Therapeutic potential of mesenchymal stromal cells and MSC conditioned medium in amyotrophic lateral sclerosis (ALS) - in vitro evidence from primary motor neuron cultures, NSC-34 cells, astrocytes and microglia. PLoS One. 2013;8:e72926.

32. Connick P, Chandran S. Mesenchymal stromal cell transplantation modulates neuroinflammatory milieu in amyotrophic lateral sclerosis. Cytotherapy. 2014;16:1031-1032.

33. Mazzini L, Fagioli F, Boccaletti R, et al. Stem cell therapy in amyotrophic lateral sclerosis: a methodological approach in humans. Amyotroph Lateral Scler Other Motor Neuron Disord. 2003;4:158-161.

34. Mazzini L, Mareschi K, Ferrero I, et al. Autologous mesenchymal stem cells: clinical applications in amyotrophic lateral sclerosis. Neurol Res. 2006;28:523-526.

35. Mazzini L, Mareschi K, Ferrero I, et al. Stem cell treatment in amyotrophic lateral sclerosis. J Neurol Sci. 2008;265:78-83.

36. Mazzini L, Ferrero I, Luparello V, et al. Mesenchymal stem cell transplantation in amyotrophic lateral sclerosis: a Phase I clinical trial. Exp Neurol. 2010;223:229-237.

37. Karussis D, Karageorgiou C, Vaknin-Dembinsky A, et al. Safety and immunological effects of mesenchymal stem cell transplantation in patients with multiple sclerosis and amyotrophic lateral sclerosis. Arch Neurol. 2010;67:1187-1194.

38. Cho GW, Noh MY, Kim HY, Koh SH, Kim KS, Kim SH. Bone marrowderived stromal cells from amyotrophic lateral sclerosis patients have diminished stem cell capacity. Stem Cells Dev. 2010;19:1035-1042.

39. Bossolasco P, Cova L, Calzarossa C, et al. Metalloproteinase alterations in the bone marrow of ALS patients. J Mol Med (Berl). 2010;88: $553-564$.

40. Martínez HR, Marioni SS, Escamilla Ocañas CE, Gonzalez Garza MT, Moreno-Cuevas JE. Amyotrophic lateral sclerosis in pregnancy: clinical outcome during the post-partum period after stem cell transplantation into the frontal motor cortex. Cytotherapy. 2014;16:402-405.

41. Huang H, Chen L, Xi H, et al. [Olfactory ensheathing cells transplantation for central nervous system diseases in 1255 patients]. Zhongguo Xiu Fu Chong Jian Wai Ke Za Zhi. 2009;23:14-20. Chinese.

42. Chen L, Huang H, Xi H, et al. Intracranial transplant of olfactory ensheathing cells in children and adolescents with cerebral palsy: a randomized controlled clinical trial. Cell Transplant. 2010;19:185-191.

43. Chen L, Huang H, Zhang J, et al. [Short-term outcome of olfactory ensheathing cells transplantation for treatment of amyotrophic lateral sclerosis]. Zhongguo Xiu Fu Chong Jian Wai Ke Za Zhi. 2007;21: 961-966. Chinese.

44. Huang H, Tan K, Chen L, et al. [MR spectroscopy evaluation and short-term outcome of olfactory ensheathing cells transplantation in amyotrophic lateral sclerosis patients]. Zhongguo Xiu Fu Chong Jian Wai Ke Za Zhi. 2007;21:52-57. Chinese.

45. Huang H, Chen L, Xi H, et al. Fetal olfactory ensheathing cells transplantation in amyotrophic lateral sclerosis patients: a controlled pilot study. Clin Transplant. 2008;22:710-718.

46. Chen L, Chen D, Xi H, et al. Olfactory ensheathing cell neurorestorotherapy for amyotrophic lateral sclerosis patients: benefits from multiple transplantations. Cell Transplant. 2012;21 Suppl 1:S65-S77. 
47. Cashman N, Tan LY, Krieger C, et al. Pilot study of granulocyte colony stimulating factor (G-CSF)-mobilized peripheral blood stem cells in amyotrophic lateral sclerosis (ALS). Muscle Nerve. 2008;37: 620-625.

48. Appel SH, Engelhardt JI, Henkel JS, et al. Hematopoietic stem cell transplantation in patients with sporadic amyotrophic lateral sclerosis. Neurology. 2008;71:1326-1334.

49. Deda H, Inci MC, Kürekçi AE, et al. Treatment of amyotrophic lateral sclerosis patients by autologous bone marrow-derived hematopoietic stem cell transplantation: a 1-year follow-up. Cytotherapy. 2009;11: $18-25$.

50. Martinez HR, Gonzalez-Garza MT, Moreno-Cuevas JE, Caro E, Gutierrez-Jimenez E, Segura JJ. Stem-cell transplantation into the frontal motor cortex in amyotrophic lateral sclerosis patients. Cytotherapy. 2009; 11:26-34.

51. Riley J, Federici T, Polak M, et al. Intraspinal stem cell transplantation in amyotrophic lateral sclerosis: a phase I safety trial, technical note, and lumbar safety outcomes. Neurosurgery. 2012;71:405-416.

52. Riley J, Glass J, Feldman EL, et al. Intraspinal stem cell transplantation in amyotrophic lateral sclerosis: a phase I trial, cervical microinjection, and final surgical safety outcomes. Neurosurgery. 2014;74:77-87.

53. Feldman EL, Boulis NM, Hur J, et al. Intraspinal neural stem cell transplantation in amyotrophic lateral sclerosis: phase 1 trial outcomes. Ann Neurol. 2014;75:363-373.

54. Aebischer P, Pochon NA, Heyd B, et al. Gene therapy for amyotrophic lateral sclerosis (ALS) using a polymer encapsulated xenogenic cell line engineered to secrete hCNTF. Hum Gene Ther. 1996;7:851-860.

55. Aebischer P, Schluep M, Deglon N, et al. Intrathecal delivery of CNTF using encapsulated genetically modified xenogeneic cells in amyotrophic lateral sclerosis patients. Nat Med. 1996;2:696-699.
56. Zurn AD, Henry H, Schluep M, et al. Evaluation of an intrathecal immune response in amyotrophic lateral sclerosis patients implanted with encapsulated genetically engineered xenogeneic cells. Cell Transplant. 2000;9:471-484.

57. Ramón-Cueto A, Avila J. Olfactory ensheathing glia: properties and function. Brain Res Bull. 1998;46:175-187.

58. LiY, Bao J, Khatibi NH, et al. Olfactory ensheathing cell transplantation into spinal cord prolongs the survival of mutant SOD1 (G93A) ALS rats through neuroprotection and remyelination. Anat Rec (Hoboken). 2011;294:847-857.

59. LiY, Chen L, Zhao Y, et al. Intracranial transplant of olfactory ensheathing cells can protect both upper and lower motor neurons in amyotrophic lateral sclerosis. Cell Transplant. 2013;22 Suppl 1:S51-S65.

60. Zhao CP, Zhang C, Zhou SN, et al. Human mesenchymal stromal cells ameliorate the phenotype of SOD1-G93A ALS mice. Cytotherapy. 2007;9:414-426.

61. Vercelli A, Mereuta OM, Garbossa D, et al. Human mesenchymal stem cell transplantation extends survival, improves motor performance and decreases neuroinflammation in mouse model of amyotrophic lateral sclerosis. Neurobiol Dis. 2008;31:395-405.

62. Dileone M, Profice P, Pilato F, et al. Repetitive transcranial magnetic stimulation for ALS. CNS Neurol Disord Drug Targets. 2010;9: 331-334.

63. Goyal NA, Mozaffar T. Experimental trials in amyotrophic lateral sclerosis: a review of recently completed, ongoing and planned trials using existing and novel drugs. Expert Opin Investig Drugs. 2014;23:1-11.

\section{Publish your work in this journal}

The Journal of Neurorestoratology is an international, peer-reviewed, open access online journal publishing original research and review articles on the subject of Neurorestoratology. To provide complete coverage of this revolutionary field the Journal of Neurorestoratology will report on relevant experimental research, technological advances, and

\section{Dovepress}

clinical achievements. The manuscript management system is completely online and includes a very quick and fair peer-review system, which is all easy to use. Visit http://www.dovepress.com/testimonials.php to read real quotes from published authors.

Submit your manuscript here: http://www.dovepress.com/journal-of-neurorestoratology-journal 